\title{
Effects of Procyclidine on Eye Movements in Schizophrenia
}

\author{
Ulrich Ettinger',2, Veena Kumari ${ }^{1,3}$, Elizabeth Zachariah', Adrian Galea', Trevor J Crawford ${ }^{4}$, Philip J Corr ${ }^{2}$, \\ David Taylor ${ }^{5}$, Mrigendra Das' and Tonmoy Sharma*,6
}

'Division of Psychological Medicine, Institute of Psychiatry, UK; ${ }^{2}$ Department of Psychology, Goldsmiths College, University of London, UK;

${ }^{3}$ Department of Psychology, Institute of Psychiatry, UK; ${ }^{4}$ Mental Health and Neural Systems Research Unit, Psychology Department, Lancaster

University, UK; ${ }^{5}$ Pharmacy, The Maudsley Hospital, London, UK; ${ }^{6}$ Clinical Neuroscience Research Centre, Dartford, UK

\begin{abstract}
Smooth pursuit eye movement (SPEM) and antisaccade deficits are observed in the schizophrenia spectrum and have been used to study the pathophysiology as well as the genetic basis of this condition. The neurotransmitter acetylcholine has been implicated in a number of cognitive processes thought to underlie SPEM and antisaccade performance. This study investigates effects on eye movements of procyclidine, an anticholinergic drug often administered to schizophrenic patients. A total of I 3 patients completed a double-blind placebo-controlled crossover design, receiving $15 \mathrm{mg}$ procyclidine and placebo. Seven participants received procyclidine first and placebo second, six participants were tested in the reverse order. SPEM and antisaccade (as well as fixation and prosaccade) eye movements were recorded using infrared oculography. Results showed that procyclidine overall, relative to placebo, mildly worsened SPEM performance, as indicated by nonsignificantly reduced gain $(p=0.08)$ and increased frequency of intrusive anticipatory saccades during pursuit $(p=0.06)$. A significant interaction of group and order of administration indicated that procyclidine increased the rate of antisaccade reflexive errors only when administered first; the opposite pattern was observed when placebo was administered first, likely due to the operation of practice effects at second assessment. These findings indicate that acute administration of a clinically relevant dose of procyclidine leads to mild impairments in eye movement performance in schizophrenic patients, suggesting the need to consider this compound in oculomotor studies in schizophrenia. The action of this anticholinergic drug on oculomotor performance is consistent with the hypothesized role of the cholinergic system in the cognitive mechanisms of attention and working memory, processes thought to underlie SPEM and antisaccade performance. Effects of order of administration and practice on the antisaccade task suggest that these factors need to be taken into consideration in future pharmacological studies.

Neuropsychopharmacology (2003) 28, 2199-2208, advance online publication, 27 August 2003; doi: I0.1038/sj.npp. I 300286
\end{abstract}

Keywords: schizophrenia; procyclidine; anticholinergic; smooth pursuit eye movements; antisaccade; cognition

\section{INTRODUCTION}

Procyclidine (1-cyclohexyl-1-phenyl-3-(pyrrolidin-1-yl)propan-1-ol hydrochloride) is a synthetic anticholinergic agent (Whiteman et al, 1985). While previously used in the treatment of Parkinson's disease (Brocks, 1999), it is now most commonly administered to schizophrenic patients in order to alleviate antipsychotic-induced side effects (Mindham et al, 1977; Spohn and Strauss, 1989).

Central cholinergic projections are extremely diffuse. The key pathways arise from cholinergic neurons in the midand hindbrain, such as the nucleus basalis magnocellularis of Meynert, and project onto cortical neurons (Deutch and

Financial Support: AstraZeneca (UK) and Beit Memorial Foundation. *Correspondence: Dr T Sharma, Clinical Neuroscience Research Centre, 7 Twisleton Court, Priory Hill, Dartford, Kent, DAI 2EN, UK, Tel: + 44 I 322286 862, Fax: + 44 |322 286 86।,

E-mail: t.sharma@psychmed.org.uk

Received 27 November 2002; revised 04 June 2003; accepted 20 June 2003

Online publication: II July 2003 at http://www.acnp.org/citations/ Npp07| I 0302433/default.pdf
Roth, 1999). Procyclidine primarily antagonizes muscarinic (M) receptors M1, M2, and M4, of which M1 and M4 are diffusely distributed throughout the brain; M2 is the heart isoform of the receptor and is not widely found in other organs (Waxham, 1999). Procyclidine also acts, less strongly, on $\mathrm{N}$-methyl-D-aspartate (NMDA) glutamine and nicotinic acetylcholine receptors (Whiteman et al, 1985).

The neurotransmitter acetylcholine has been implicated in cognition. Both animal and human studies have demonstrated a role of central cholinergic systems in memory, attention, and learning (Everitt and Robbins, 1997; Francis et al, 1999; McGaughy et al, 2000). The role of acetylcholine in cognition is also compatible with the cognitive degeneration observed in Alzheimer's disease, a condition with known pathology of basal forebrain cholinergic neurons (Francis et al, 1999). Given this evidence, as well as the evidence of cognitive dysfunction in schizophrenia (Sharma and Harvey, 2000), it is of particular interest to study the effects of clinical doses of anticholinergic compounds such as procyclidine on cognition.

Recently, Kumari et al (2001) observed disrupted prepulse inhibition (PPI) in healthy individuals after 
administration of $15 \mathrm{mg}$ (but not $10 \mathrm{mg}$ ) of procyclidine. PPI is an operational measure of sensorimotor gating that has been shown to be impaired in schizophrenia (Braff et al, 2001; Kumari, 2000; Swerdlow et al, 2000). Zachariah et al (2002) observed impairments on a variety of cognitive tests in healthy individuals after procyclidine administration. Sharma et al (2002) found reduced heart rate and alertness (assessed using the critical flicker fusion threshold paradigm) after $15 \mathrm{mg}$ (but not $10 \mathrm{mg}$ ) of procyclidine in healthy individuals. Taken together, these reports suggest that procyclidine dose dependently impairs neurocognitive function and reduces alertness in healthy individuals. Relatedly, Mori et al (2002) observed improvements in memory and increases in regional cerebral blood flow in schizophrenic patients after withdrawal from anticholinergic treatment, whereas Kumari et al (2003) observed detrimental effects of acute administration of $15 \mathrm{mg}$ procyclidine on PPI in this population.

Eye movements are good indicators of neurocognitive function that have been used to study the pathophysiology of schizophrenia and other neuropsychiatric disorders (Broerse et al, 2001; Kennard et al, 1994; Ross, 2000). Additionally, certain eye movement deficits have been proposed to be schizophrenia spectrum endophenotypes. An endophenotype is a biological or behavioral deficit thought to be a more direct expression of a disease gene than the disease phenotype. Endophenotypes have been used with profit in genetic linkage analyses where the disease phenotype failed to show linkage (Leboyer et al, 1998). The most promising oculomotor endophenotypes for schizophrenia are smooth pursuit eye movement (SPEM) and antisaccade deficits. In the SPEM task, the participant is required to follow, with their eyes, a slowly moving visual target. In the antisaccade task, the participant is required to initiate an abrupt, saccadic eye movement in the opposite direction to that of the visual target. Both tasks meet a number of reliability and validity criteria for being useful measures of schizophrenia endophenotypes: schizophrenic patients and their unaffected first-degree relatives as well as individuals with schizotypal signs and symptoms show reduced SPEM accuracy and increased antisaccade errors (viz reflexive glances to the target) (Calkins and Iacono, 2000; Clementz, 1998; Levy et al, 1994).

Studies of the cognitive component processes of SPEM and antisaccade performance have suggested that task performance relies on recruitment of overt and covert attention (Kristjánsson et al, 2001; Roitman et al, 1997; Schwartz et al, 2001; Sweeney et al, 1994) as well as response inhibition and working memory (Mitchell et al, 2002; Roberts et al, 1994; Stuyven et al, 2000). All these processes are likely to be at least partly mediated by central cholinergic pathways (McGaughy et al, 2000). A recent study showed that both SPEM and antisaccade performance improved with the administration of nicotine in schizophrenic patients and healthy controls, likely due to cholinergic mechanisms (Dépatie et al, 2002). Given the disruptive effects of anticholinergics on some of the cognitive processes hypothesized to mediate successful SPEM and antisaccade performance, it is important to determine the effects of anticholinergic agents on these oculomotor measures.

The present study is the first to investigate the acute effects of an anticholinergic drug on oculomotor control in people with schizophrenia. Oculomotor tasks are an ideal tool for probing the effects of an anticholinergic drug on neurocognitive function, as they allow the precise and objective assessment of specific cognitive component processes. People with schizophrenia are an important population for such an investigation, as (1) a proportion of them are prescribed anticholinergic compounds and (2) they display relatively circumscribed deficits in oculomotor function.

We, therefore, aimed to quantify the effects of acute procyclidine administration on SPEM and antisaccade measures (as well as the oculomotor control tasks of visual fixation and prosaccade) in a sample of schizophrenic patients using a double-blind, placebo-controlled crossover design. Given the role of the cholinergic system in the cognitive processes implicated in smooth pursuit and antisaccade eye movements, impaired performance was hypothesized after administration of procyclidine but not placebo. Additionally, given the observation of practice effects on antisaccades in previous pharmacological studies (Green et al, 2000; Klein et al, 2002), we investigated whether oculomotor performance was affected by procyclidine as a function of drug administration order.

\section{METHOD}

\section{Participants}

A total of 15 patients with a DSM-IV diagnosis of schizophrenia were recruited into the study. Two of these refused second assessment, thus leaving a final sample size of 13 patients (seven males, six females; mean age $=35.54$; $\mathrm{SD}=11.59$ ). All patients were treated with one of two atypical drugs with low intrinsic anticholinergic properties, viz. risperidone or quetiapine. Five patients were on quetiapine (dose range: $100-300 \mathrm{mg}$ daily) and eight were on risperidone (dose range: $2-6 \mathrm{mg}$ daily). Patients were not on any anticholinergic medication for at least 6 months prior to taking part in the study, although six patients had been prescribed procyclidine in the past. All patients were required to have stable symptoms for at least 1 month before taking part in the study and reported to be free from drug abuse. Diagnoses were established 1 week before the first oculomotor assessment using the Structured Clinical Interview for the Diagnostic and Statistical Manual of Mental Disorders (SCID) (First et al, 1996) and current symptoms were rated using the Positive and Negative Syndrome Scale (PANSS) (Kay et al, 1987).

All patients provided written consent after detailed explanations of the study procedures had been given to them. The study was approved by the Ethics Committee of the Institute of Psychiatry, London.

\section{Eye Movement Tasks}

Stimuli were displayed on a 17 -in monitor. A white target of circular shape (approximately $0.3^{\circ}$ of visual angle) was presented on a black background. Participants sat in a comfortable chair at a distance of $57 \mathrm{~cm}$ from the monitor. Head movements were minimized using a chinrest. Testing took place in a quiet, darkened room. A three-point calibration task $\left(+12,0,-12^{\circ}\right.$; each stimulus 
duration $=1000 \mathrm{~ms}$ ) was carried out before each of the following tasks. Tasks were administered in the following order: fixation, antisaccade, prosaccade, smooth pursuit.

\section{Smooth Pursuit}

A triangular target waveform was used at $12,24,36$, and $48^{\circ}$ s. The target was initially placed in the central position $\left(0^{\circ}\right)$ and then moved horizontally to $\pm 12^{\circ}$, where it reversed abruptly and moved to the opposite side. The direction of the first ramp was random (right or left). The first ramp (from 0 to $\pm 12^{\circ}$ ) was considered practice and was not analyzed. A total of 16.5 half-cycles were run at each target velocity. Participants were instructed to keep their eyes on the target wherever it moved.

\section{Fixation}

The target remained stationary in each target location $\left( \pm 12,0, \pm 12,0^{\circ}\right)$ for durations of $20 \mathrm{~s}$. Participants were instructed to focus their gaze on the target as accurately as possible. Data from one patient (on procyclidine) could not be collected due to lack of compliance. Data from a different patient (on placebo) were not usable due to data storage error.

\section{Antisaccade}

An antisaccade trial began with the target in the central location for a random duration of 1000-2000 ms. The target then stepped to one of four peripheral locations $( \pm 6$, $\pm 12^{\circ}$ ) where it remained for $1000 \mathrm{~ms}$. Each peripheral location was used 15 times, resulting in a total of 60 trials. The sequence of peripheral target presentations was random. Four practice trials using each target location once were carried out before the experimental trials and could be repeated if necessary. Participants were instructed to look at the target while in the central position and redirect their gaze to the exact mirror image location of the target as soon as it moved to the side. Data from one patient (on procyclidine) could not be collected due to lack of compliance.

\section{Prosaccade}

The prosaccade task was identical to the antisaccade task. However, on this occasion participants were instructed to follow the target as quickly and accurately as possible.

\section{Eye Movement Recording}

Eye movements were recorded using infrared oculography (IRIS model 6500; Skalar Medical BV, Delft, The Netherlands) (Reulen et al, 1988). Horizontal recordings with the IRIS system can be made within a range of $\pm 30^{\circ}$. The linearity of the system lies within $3 \%$ between $\pm 25^{\circ}$ of horizontal recordings. Recordings were taken from the left eye only. Eye and target positions were logged by the eyetracker. Signals were converted from analogue to digital by a four-channel analogue-to-digital converter card with 12 bits resolution per channel and a sampling frequency of $500 \mathrm{~Hz}$. Data were saved onto hard disk for further analysis.

\section{Eye Movement Analysis}

The purpose-written software package EYEMAP (Version 2.1; AMTech GmbH, Weinheim, Germany) (see, eg Crawford et al, 1998; Lencer et al, 1999) was used for analysis of eye movement data. Inter- and intrarater reliabilities for analyses with EYEMAP in our laboratory were high for the measures reported below, ranging from $r=0.85$ to 0.99 . Data were scored blind to drug and group status. Eye-blinks in all tasks were identified by visual inspection of position and velocity charts. The oculomotor tasks used here have very good temporal stability and internal consistency (Ettinger et al, 2003).

\section{Smooth Pursuit}

SPEM data were smoothed twice using a five-point central averaging filter. The key performance measure of pursuit gain was obtained by dividing eye velocity by target velocity at mid-cycle, steady-state pursuit for each half-cycle; scores were averaged across half-cycles for each target velocity.

Saccades during pursuit were counted on the basis of a criterion of minimum amplitude $\left(1.5^{\circ}\right)$ and velocity $(30 \%)$. The velocity criterion allowed the detection of a saccade if its velocity exceeded (by $30 \%$ s) the average velocity of the preceding $50 \mathrm{~ms}$. Anticipatory saccades (AS) were defined as intrusive saccades in the target direction that took the eye ahead of the target. AS were followed either by slowing or cessation of pursuit. Following Ross et al (1999b), AS were included on the basis of a small minimum amplitude criterion $\left(1.5^{\circ}\right)$. Catch-up saccades (CUS) were defined as compensatory saccades in the target direction that served to reduce position error, that is, to bring the eye closer to the target. CUS always began with the eye behind the target. If a saccade was initiated behind the target and ended ahead of it, it was classified as an AS if more than half of the amplitude moved the eye ahead of the target. If more than half of the amplitude was spent behind the target, that is, reducing position error, the saccade was considered a CUS (Ross et al, 1999a). The number of AS and CUS was counted for each velocity and divided by the duration of pursuit, to yield measures of saccadic frequency $(\mathrm{N} / \mathrm{s})$.

Back-up saccades and square-wave jerks were also observed, but occurred infrequently and were therefore omitted from statistical analysis. Previous studies have suggested that these types of saccades are not consistently affected in the schizophrenia spectrum (Clementz et al, 1990; Lencer et al, 1999; Radant and Hommer, 1992).

\section{Fixation}

Visual fixation performance was assessed by calculating the frequency of saccades $(\mathrm{N} / \mathrm{s})$ based on the criteria of minimum amplitude $\left(1.5^{\circ}\right)$ and minimum velocity $\left(30^{\circ} / \mathrm{s}\right)$.

\section{Antisaccade}

Detection of saccades was based on the above criteria of minimum amplitude and velocity as well as a minimum latency to target of $100 \mathrm{~ms}$. Saccades that were preceded immediately by an eye-blink, another saccade (such as a 
square-wave jerk), or unstable fixation were not included in this analysis; however, these events were rare.

Antisaccade errors were counted when the participant initiated a primary saccade towards the peripheral target; a correct antisaccade trial was counted when the participant performed a primary saccade in opposite direction to the peripheral target. The error rate reflects the percentage of error trials over the total number of valid antisaccade trials (excluding, eg eye-blink trials). A corrective saccade was counted when an error was followed by a saccade in the opposite direction. Antisaccade latency was defined as the time (in milliseconds) from target appearance to saccade initiation of correct trials. Primary antisaccade gain (antisaccade amplitude divided by target amplitude multiplied by 100) was calculated as a measure of spatial accuracy (\%).

\section{Prosaccade}

Prosaccade gain (\%) and latency (milliseconds) were calculated based on the above criteria.

\section{Drug Dose and Administration}

Participants were administered oral $15 \mathrm{mg}$ procyclidine or a placebo (200 mg ascorbic acid) of identical appearance on two occasions under double-blind conditions. Intervals between assessments ranged between 10 and 14 days. Participants were quasi-randomly assigned to one of two orders of drug administration: Seven participants received procyclidine first and placebo second (Group 1); six participants were assessed in the reverse order (Group 2). All patients received placebo or procyclidine between 0900 and 1145 (kept constant for each participant within $\pm 30 \mathrm{~min}$ across both sessions) to control for effects of time of day on drug metabolism. A dose of $15 \mathrm{mg}$ procyclidine was deemed appropriate as it was clinically relevant and has been shown to affect central nervous system processing in healthy individuals in the absence of severe side effects (Kumari et al, 2001; Sharma et al, 2002; Zachariah et al, 2002).

Eye movements were assessed between 4 and $5 \mathrm{~h}$ postdrug administration, after the administration of other cognitive tasks not reported here. This postadministration duration is well within the plasma elimination half-life of procyclidine of $12 \mathrm{~h}$ (Whiteman et al, 1985). A previous study showed that this duration provided near-maximal plasma concentration of orally administered procyclidine (Whiteman et al, 1985). A self-rating measure of alertness/sedation was taken shortly before drug administration and shortly before or after eye movement assessment. This measure was a $100 \mathrm{~mm}$ visual analogue scale, ranging from 'alert' to 'drowsy' (Bond and Lader, 1974).

\section{Statistical Analysis}

Statistical analyses were carried out using SPSS Release 10.0.7 (SPSS Inc., Chicago, IL). A number of oculomotor variables were slightly skewed. However, as both positive $(<1.63)$ and negative $(>-1.37)$ skewness values were only moderate and no obvious outliers were observed, these distributions were not considered to be a significant challenge to the normality assumption of the parametric statistical analyses reported below.

Groups 1 (procyclidine first) and 2 (placebo first) were compared on PANSS ratings and age using analysis of variance (ANOVA)

Each SPEM variable (gain, AS, CUS) was analyzed using a $2 \times 4 \times 2$ repeated measures ANOVA with drug (procyclidine, placebo) and velocity $\left(12,24,36,48^{\circ} / \mathrm{s}\right)$ as withinsubjects factors and order (procyclidine first, placebo first) as between-subjects factor. Each saccadic and fixation variable was analyzed using a $2 \times 2$ repeated measures ANOVA with drug (procyclidine, placebo) as withinsubjects factor and order (procyclidine first, placebo first) as between-subjects factor.

Effect sizes for within-group comparisons of treatment effects were calculated using the formula $\mu_{1}-\mu_{2} / \mathrm{SD}_{\text {diff }}$ where $\mu_{1}$ is the mean of variable 1 (on procyclidine), $\mu_{2}$ the mean of variable 2 (on placebo), and $\mathrm{SD}_{\text {diff }}$ the standard deviation of the difference scores.

To assess the effects of drug on alertness at the time of eye movement assessment, a $2 \times 2 \times 2$ repeated measures ANOVA was carried out with time (baseline, eye movement assessment) and drug (procyclidine, placebo) as withinsubjects factors and order (procyclidine first, placebo first) as between-subjects factor.

\section{RESULTS}

Descriptive statistics of oculomotor variables are given in Table 1; ANOVA results are given in Table 2. The average antisaccade correction rate was $92.48 \%(S D=10.56)$ after administration of procyclidine and $90.43 \% \quad(S D=16.48)$ after placebo.

\section{Effects of SPEM Target Velocity, Age, Symptom Ratings, and Sex}

For SPEM, there were significant effects of target velocity on gain $(\mathrm{F}[3,33]=49.20 ; p<0.001)$, CUS $(\mathrm{F}[3,33]=107.73$; $p<0.001)$, and AS frequency $(\mathrm{F}[3,33]=8.90 ; p<0.001)$. There were no velocity $\times$ order (all $p>0.08)$ or velocity $\times$ order $\times$ drug interactions (all $p>0.14$ ). The two groups (Group 1, Group 2) did not differ on age $(p=0.85)$ or PANSS ratings (all $p>0.37$ ).

There were no effects of sex (all $p>0.07$ ) on oculomotor performance. Age was correlated with antisaccade gain on drug $(r=0.69 ; p=0.01)$, antisaccade latency on placebo $(r=0.69 ; p=0.009)$, prosaccade latency on drug $(r=0.81$; $p=0.001)$, CUS frequency on placebo $(r=0.59 ; p=0.04)$, and SPEM gain on placebo at $48^{\circ} / \mathrm{s}(r=-0.58 ; p=0.04)$, but not at other velocities or during administration of procyclidine (all $p>0.06$ ). Difference scores between performance on procyclidine and placebo were then calculated in order to investigate the association between age and the effects of drug on performance: age was not correlated with drug-induced changes on any dependent measures (all $p>0.09$ ).

\section{Effects of Procyclidine on SPEM and Fixation}

There was a nonsignificant trend towards reduced SPEM gain with procyclidine compared to placebo (Figure 1); 
Table I Means (SD) of Oculomotor Variables by Condition

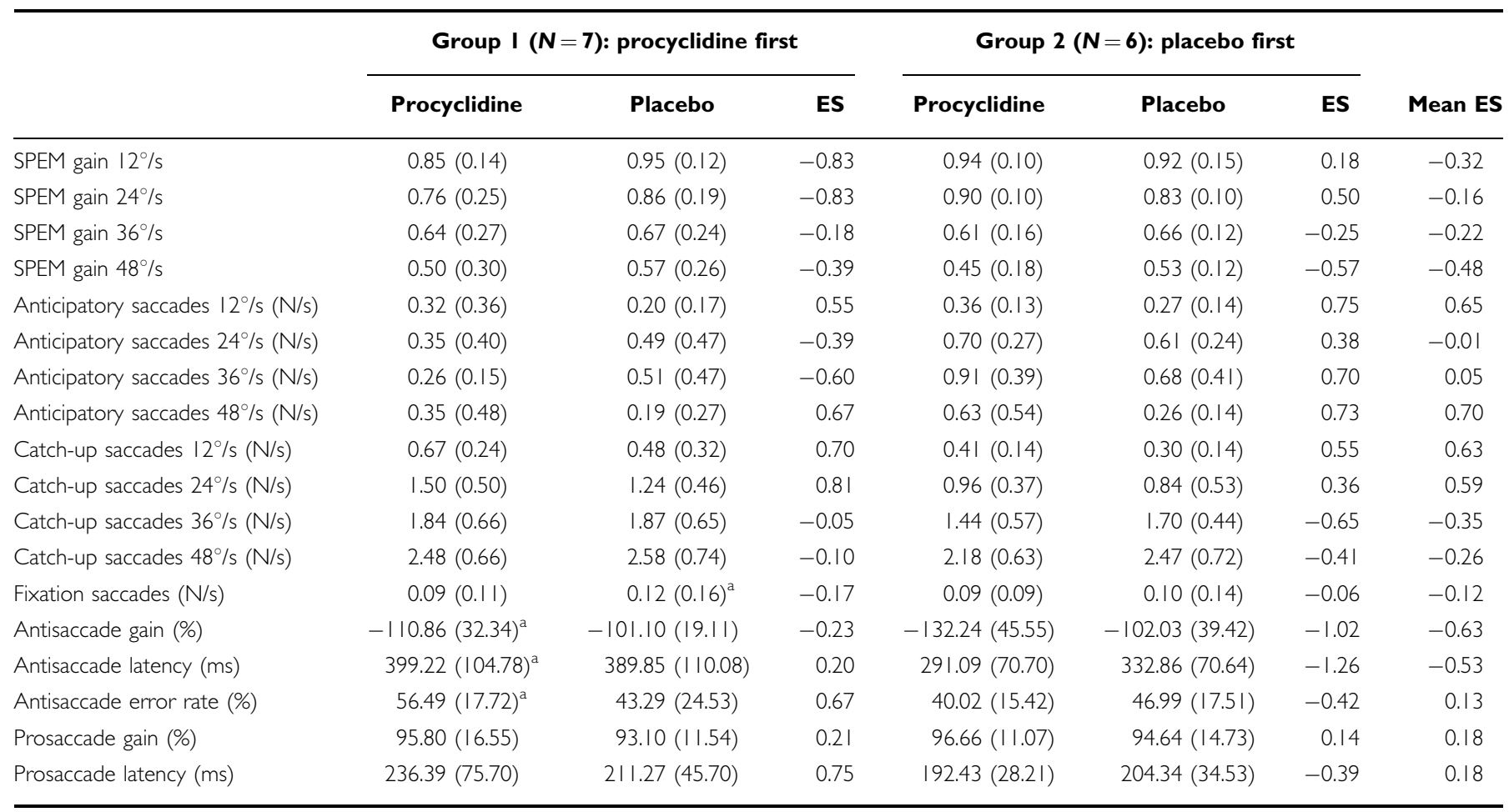

${ }^{\mathrm{a}} \mathrm{N}=6 ; \mathrm{ES}=$ effect size.

Negative effect sizes for SPEM gain indicate worse performance with administration of procyclidine. Positive effect sizes for frequency of saccades during SPEM and fixation, antisaccade latency, antisaccade error rate, and prosaccade latency indicate worse performance with the administration of procyclidine. The effect sizes for antisaccade and prosaccade gain indicate larger saccades with administration of procyclidine.

Cohen (1988) considers effect sizes of 0.2 'small', 0.5 'medium', and 0.8 'large'.

Table 2 Analysis of Variance Results for Effects of Drug, Order, and Drug $\times$ Order Interactions on Oculomotor Performance

\begin{tabular}{|c|c|c|c|c|c|c|c|c|c|}
\hline & \multicolumn{3}{|c|}{ Effect of drug } & \multicolumn{3}{|c|}{ Effect of order } & \multicolumn{3}{|c|}{ Effect of drug $\times$ order } \\
\hline & $\mathbf{F}$ & df & $p$ & $\mathbf{F}$ & df & $p$ & $\mathbf{F}$ & df & $p$ \\
\hline Anticipatory saccade frequency & 4.37 & I,I। & 0.06 & 2.21 & $|| 1$, & 0.17 & 7.86 & 1,11 & 0.02 \\
\hline Catch-up saccade frequency & 0.01 & I,I I & 0.99 & 2.11 & I,I I & 0.17 & 0.74 & I,I I & 0.41 \\
\hline Antisaccade latency & 0.96 & 1,10 & 0.35 & 2.21 & 1,10 & 0.17 & 6.39 & 1,10 & 0.03 \\
\hline Antisaccade error rate & 1.29 & 1,10 & 0.28 & 0.15 & 1,10 & 0.70 & 6.06 & 1,10 & 0.03 \\
\hline Prosaccade gain & 0.40 & I,II & 0.54 & 0.03 & I,II & 0.86 & 0.01 & I,I I & 0.93 \\
\hline Prosaccade latency & 0.54 & I,I I & 0.48 & 0.90 & 1,11 & 0.36 & 4.28 & 1,11 & 0.06 \\
\hline
\end{tabular}

there was no effect of order or order $\times$ drug interaction on this variable (for $\mathrm{F}$ and $p$ values see Table 2). A similar nonsignificant trend emerged for AS frequency, with an increased frequency after procyclidine compared to placebo. Additionally, there was a drug $\times$ order interaction but no effect of order. The interaction indicates that AS frequency was increased by procyclidine when administered second (after placebo); when procyclidine was administered first (before placebo), the reverse pattern was observed. There were no significant main or interaction effects on CUS frequency or the frequency of saccades during fixation.

\section{Effects of Procyclidine on Antisaccade and Prosaccade}

Antisaccade gain scores were increased by procyclidine compared to placebo at trend level (Table 2); there was no effect of order or drug $\times$ order interaction. There was a significant drug $\times$ order interaction on antisaccade latency but no main effects of drug or order: Procyclidine was associated with shorter latencies when it was administered second. There was a significant drug $\times$ order interaction, but no main effects of drug or order on antisaccade error rate: Procyclidine increased the error rate only when administered first (Figure 2). 


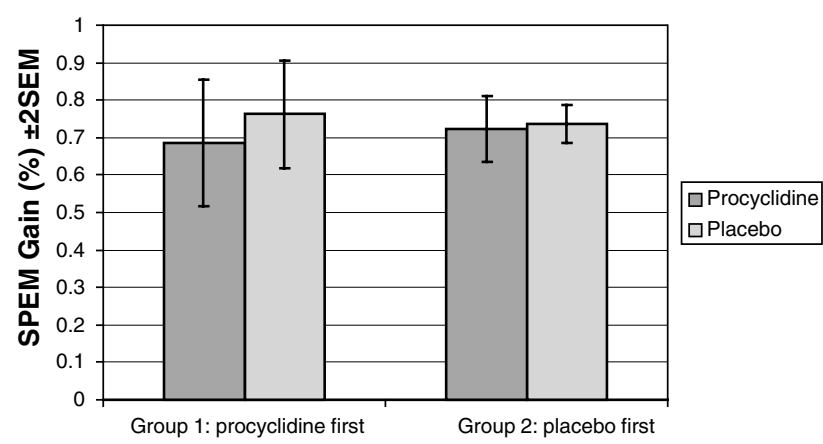

Figure I Smooth pursuit gain after the administration of procyclidine and placebo.

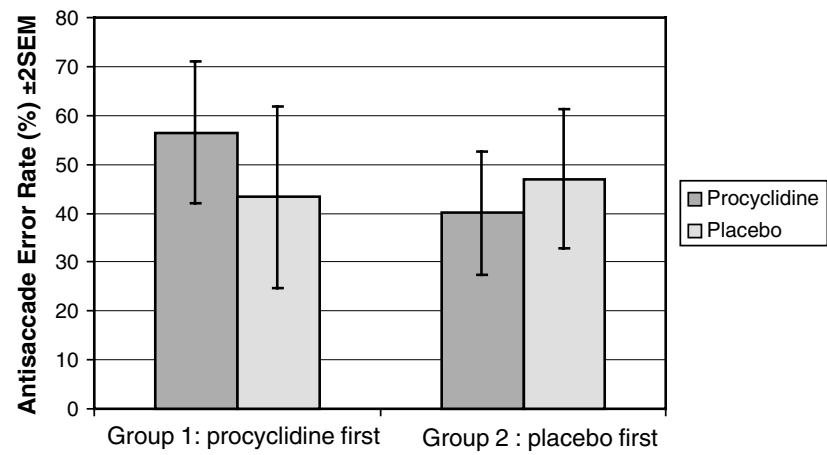

Figure 2 Antisaccade error rate after the administration of procyclidine and placebo.

There was a significant drug $\times$ order interaction but no main effects of drug or order on prosaccade latency. Procyclidine was associated with shorter latency when administered second; the reverse pattern was observed when procyclidine was administered first. There were no main or interaction effects on prosaccade gain.

\section{Effects of Procyclidine on Alertness}

There were no effects of drug, time or order, or drug $\times$ order, drug $\times$ time, time $\times$ order, or drug $\times$ time $\times$ order interactions on ratings of alertness (all $p \geqslant 0.09$ )

\section{DISCUSSION}

\section{Key Findings}

The key findings from this study are as follows: (1) In patients with schizophrenia, acute administration of procyclidine produced a nonsignificant trend towards worsened smooth pursuit. (2) The effects of procyclidine on some variables were affected by the order in which procyclidine and placebo were administered.

\section{Effects of Procyclidine}

Procyclidine nonsignificantly reduced the key smooth pursuit measure of velocity gain (ie the match of eye and target velocity). Additionally, procyclidine led to a nonsignificant overall increase in the frequency of intrusive AS during pursuit. It is possible that these effects could have reached conventional levels of statistical significance if a larger sample had been used.

As can be seen from Table 1, reductions in SPEM gain with procyclidine reached effect sizes that ranged from small $(-0.18)$ to large $(-0.83)$, while at two target velocities (in the group receiving placebo first) small-to-moderate effects were observed in the opposite direction. When effect sizes were averaged across groups, gain reductions of small and moderate effect were observed. Similarly, effect sizes for AS frequency varied, with six of eight comparisons showing deterioration with procyclidine $(0.38-0.75)$, while two comparisons showed an effect in the opposite direction. A significant interaction indicated that the effect of procyclidine on AS frequency appeared to be mediated by order of drug administration. Procyclidine led to a consistent increase in AS frequency when administered second, but a less consistent pattern was observed when procyclidine was administered first. The reasons for this interaction are unclear. It is important in this context, however, that the main effects of procyclidine on AS frequency were adverse, in line with the study's hypotheses, leading to a nonsignificant overall increase of this type of intrusive saccade. Similarly, while the aggregate effect of procyclidine on SPEM gain appeared to be detrimental, the possibility that effects of order of administration might have attained formal levels of statistical significance with a larger sample size cannot be excluded (see Figure 1).

A possible explanation for these impairments in smooth pursuit performance during procyclidine administration might be the role of the cholinergic system in attention (Everitt and Robbins, 1997). Previous studies have suggested that accurate smooth pursuit eye movements and suppression of intrusive AS require attentional processes (Roitman et al, 1997; Schwartz et al, 2001; Sweeney et al, 1994). A likely consequence of the widespread antagonistic action of procyclidine at the M1 and M4 receptors across the entire brain is a reduction in the levels of attention (Coull, 1998) or cortical arousal (Sharma et al, 2002). The lack of an effect of procyclidine on self-reported alertness/ drowsiness at the time of eye movement assessment suggests that this effect was centrally mediated.

Effects of target velocity on SPEM variables were consistent with previous research, indicating worse performance at faster velocities (Leigh and Zee, 1999).

One methodological limitation of the current SPEM analysis method might be the minimum amplitude criterion that we chose for the detection of saccades in our semiautomated analysis $\left(1.5^{\circ}\right)$, which was larger than in other studies. This conservative criterion was chosen to minimize the likelihood of artifacts due to the inclusions of small head movements that might occur during pursuit, especially in acutely medicated patients. Ross et al (1999b) have stressed the importance of this issue with respect to small anticipatory, or 'leading', saccades. The use of a smaller amplitude criterion (eg $0.5^{\circ}$ ) in our study would certainly have led to the inclusion of a greater number of saccades during pursuit. However, it is highly unlikely that this factor accounted for the (nonsignificant) effects of drug or the (significant) group by drug interactions reported 
here, particularly given that drug effects have been shown to be more pronounced for larger amplitude saccades (Carpenter, 1988).

On the antisaccade task, procyclidine adversely affected the key performance measure of error rate when administered first. When administered second, procyclidine appeared to have a weaker effect in the opposite direction. To explain this pattern of performance, both pharmacological and practice effects have to be considered.

It is a possibility that in the group receiving placebo first, performance at first assessment was slightly impaired due to psychological factors, such as the expectancy to receive a performance-impairing compound (Beecher, 1959). Participants were aware that they would on one occasion receive a compound that could have detrimental effects on their cognitive function. At the time of the second assessment (during procyclidine in this group), practice effects on antisaccade error rate might be expected (Green et al, 2000; Klein et al, 2002). Indeed, the overall pattern of reductions in error rate from the first to second assessment in Figure 2 is compatible with the operation of practice effects. However, the participants who first received the placebo would be expected to have experienced only a small practice-related reduction in error rate since the procyclidine administered at the second assessment would be expected to have an inverse effect on performance. This hypothesized pattern of effects might explain the observation of a small reduction in error rate from the first to the second assessment in this group.

In participants receiving procyclidine at first assessment, similar factors (of psychopharmacological effects and practice) may be drawn upon to explain the observed change in error rate across the two assessments. First, the adverse effects of procyclidine at first assessment (in the possible presence of expectancy effects) might have led to the substantially increased error rate in this group (56.49\%), the highest observed in this study. Second, practice effects can be expected to have led to reductions in error rate at second assessment. These expected improvements were likely to have been further strengthened by the absence of performance-impairing pharmacological effects at second assessment. In other words, the reductions in error rate from the first to the second assessment may reflect in this instance synergistic pharmacological and practice effects.

It should be noted that on most antisaccade error trials (on average $>90 \%$ ) participants initiated a corrective saccade (in the opposite direction). This observation can be taken to indicate that participants understood the task requirements and were compliant (McDowell and Clementz, 1997).

A notable feature of the current study in the context of practice effects is that all patients were treated with atypical antipsychotic drugs. Previous research has demonstrated that practice effects on cognitive tasks may be observed in patients treated with atypical, but to a lesser extent typical, antipsychotics, probably due to the effects of atypical antipsychotics on restoring patients' capacity to learn (Harvey et al, 2000).

A similar interaction of drug and order of administration on antisaccade error rate, probably due to practice effects, was observed by Klein et al (2002). In their study of individuals with attention-deficit/hyperactivity disorder
(ADHD), methylphenidate improved antisaccade errors only when administered second, with the improvement overlaid by practice effects. When administered first, the operation of practice effects at second assessment probably masked improvements effected by this compound at first assessment. In contrast to the present data pertaining to the antisaccade error rate, however, the Klein et al study also reported significant main effects of drug, possibly due to a larger sample size or factors related to the strength of the pharmacological effect.

In order to investigate effects of practice more comprehensively, the present study as well as Klein et al (2002) study should have included a third group of participants, given placebo on both occasions. In such a design, the magnitude of practice effects could have been assessed in the absence of any influence of pharmacological agents.

It is of interest to note that evidence of practice-related performance changes between sessions was obtained in this study primarily for the antisaccade but not consistently for SPEM variables (see Table 1). Previous studies have shown temporally stable SPEM performance in schizophrenic patients and healthy individuals in the absence of between-session improvements (Gooding et al, 1994). We have recently demonstrated robust practice effects on antisaccade, but not SPEM measures in healthy individuals over a period of about 2 months (Ettinger et al, 2003).

The possibility of increases in antisaccade error rate due to procyclidine administration is in accord with the role of a variety of cognitive processes in task performance and the role of the cholinergic system in these processes. Previous studies have shown that successful antisaccade performance requires intact inhibition of a prepotent response as well as working memory capacities (Mitchell et al, 2002; Roberts et al, 1994; Stuyven et al, 2000). Conversely, animal studies have shown disrupted performance on memory-sensitive tasks after inactivation of cholinergic projections (Everitt and Robbins, 1997; McGaughy et al, 2000). Antisaccade performance and working memory both involve a cortical network including, but not restricted to, the dorsolateral prefrontal cortex (Mitchell et al, 2002; Müri et al, 1998), suggesting that this area might be a possible locus for the action of procyclidine and its effects on task performance. However, neuroanatomic localization of procyclidine effects on antisaccade errors in this study is made difficult by the widespread nature of central cholinergic projections and the widely distributed occurrence of muscarinic acetylcholine receptors in the human brain.

Procyclidine also led to nonsignificantly increased, or hypermetric, antisaccade gain irrespective of the order of administration. Reduced, or hypometric, saccadic gain has been observed in schizophrenic patients treated with typical antipsychotic drugs as well as in patients with Parkinson's disease, suggesting a common influence of the Parkinsonian effects of dopamine antagonism (Crawford et al, 1989, 1995a,b; Hutton et al, 2001). It is a possibility that procyclidine administration led to the opposite pattern of increased saccadic amplitudes in this sample through its antagonist action on Parkinsonian side effects.

Effects of procyclidine on saccadic latency were moderated by the order of drug administration. Both prosaccade and antisaccade latencies were shorter with procyclidine when the drug was administered second. The opposite 
pattern was observed when procyclidine was administered first. Aizawa et al (1999) noted shortened latency and increased frequency of 'express saccades' (saccades with latencies of less than $120 \mathrm{~ms}$ ) in monkeys after injection of the cholinergic agonist nicotine into the superior colliculus, a midbrain region involved in the control of saccades. The finding of prolonged latency after administration of the cholinergic antagonist procyclidine under some conditions are compatible with this finding and with observations of the sedative effects of this drug (Sharma et al, 2002). However, it remains unclear why prosaccade and antisaccade latencies were shortened by procyclidine under some conditions. Also, comparisons between the present findings and those of Aizawa et al (1999) are tenuous as procyclidine and nicotine act on different acetylcholine receptor subtypes and due to the localized action of nicotine in the Aizawa et al study.

An alternative explanation for these complex effects of procyclidine and placebo on saccadic latency is the operation of practice effects. As Table 1 reveals, both antisaccade and prosaccade latencies were shorter at the second compared to the first assessment. These improvements in performance are similar to those reported by Klein et al (2002) over a comparable time interval.

\section{Implications}

Our findings have research and clinical implications. First, oculomotor impairments in schizophrenic patients due to procyclidine might lead to inflated between-group differences when compared to unmedicated individuals. Procyclidine might also confound studies of different antipsychotic compounds, as it is more likely to be prescribed to patients on typical antipsychotics (Leonard, 1997). However, longitudinal studies are needed to substantiate this claim.

Smooth pursuit and antisaccade deficits have been proposed as schizophrenia endophenotypes (Clementz, 1998; Levy et al, 1994; O’Driscoll et al, 1998). The present findings suggest that procyclidine should be considered in genetic studies using these endophenotypes. In linkage studies, performance impairments due to procyclidine treatment in some patients might lead to the spurious identification of gene carriers (false positives). False positives have serious effects in linkage studies, far more than false negatives (Ott, 1991). It is important to note in this context, however, that the observation of false positives would be specific to the group of schizophrenic patients, as their unaffected first-degree relatives are typically not medicated.

The second main finding of this study, the interactive effects of drug and order of administration, highlights the need to consider these factors in pharmacological research. Additionally, effects of repeated testing were demonstrated for some eye movement parameters; these effects, possibly due to task practice, may have overlaid drug effects. Future pharmacological studies should consider practice effects as well as the order of drug administration.

Clinically, cognitive dysfunction is one of the most pervasive and debilitating features of schizophrenia (Friedman et al, 1999; Sharma and Harvey, 2000) and plays an important role in the psychosocial function of sufferers
(Beiser et al, 1994; Katsanis et al, 1996; Kurtz et al, 2001; Spaulding et al, 1999). Adjunctive treatment with anticholinergic agents needs to be evaluated in light of possible neurocognitive impairments, as it may lead to further, unwanted deleterious effects on psychological function.

\section{Limitations}

The present study has a number of limitations. First, the sample size, although comparable to previous pharmacological studies, was relatively small. The sample size and low statistical power might also be the reason why some of the effects reported here (eg the main effects of drug on SPEM gain) failed to reach conventional levels of statistical significance. Replication using a larger, independent sample is, therefore, required. However, the fact that even in this small sample mild effects of a clinical dose of procyclidine on oculomotor function were observed indicates that they are likely to be clinically meaningful.

Second, there was no control group of healthy individuals. While the main focus of this investigation was to examine the effects of a clinical dose of procyclidine on eye movements in schizophrenic patients, who are often prescribed this drug, it might have been valuable to compare performance levels of the patient group to healthy individuals.

In order to obtain an indication of performance levels of healthy controls on the oculomotor tasks used here it may be valuable to inspect data reported by Ettinger et al (2003). Group means of their nonclinical sample for the key measures of SPEM gain $(12 \% \mathrm{~s}: 98.60 \%, \mathrm{SD}=8.09 ; 24 \%$ : $95.32 \%, \mathrm{SD}=10.58 ; 36 \%$ s: $89.59 \%, \mathrm{SD}=9.03 ; 48 \% \mathrm{~s}: 71.85 \%$, $\mathrm{SD}=16.00)$ and antisaccade error rate $(20.90 \%, \mathrm{SD}=15.14)$ indicate that the current patient sample, as might be expected, performed worse than healthy individuals. However, a formal statistical comparison of these two groups cannot be made due to differences in important demographic variables, and as patients in this study were administered drug/placebo, whereas participants in our previous study were not.

Third, a group of schizophrenic patients administered placebo on both occasions might have been valuable to study the effects of practice on performance measures more closely.

Fourth, future studies might wish to investigate the effects of higher doses of procyclidine on oculomotor function. While our choice of a $15 \mathrm{mg}$ dose of procyclidine was based on clinical and pharmacological considerations (Whiteman et $a l, 1985)$ as well as our previous findings, which suggested that this dose was more disruptive than $10 \mathrm{mg}$ (Kumari et al, 2001; Sharma et al, 2002; Zachariah et al, 2002), it is possible that a higher dose might have led to stronger effects on oculomotor function than those observed here.

Finally, the extent to which these findings generalize to longitudinal treatment of schizophrenic patients with procyclidine remains open. It has to be investigated how clinically relevant treatment with procyclidine over durations of several weeks or months affects smooth pursuit and antisaccade eye movements in schizophrenic patients. 


\section{REFERENCES}

Aizawa H, Kobayashi Y, Yamamoto M, Isa T (1999). Injection of nicotine into the superior colliculus facilitates occurrence of express saccades in monkeys. J Neurophysiol 82: 1642-1646.

Beecher HK (1959). Measurement of Subjective Responses: Quantitative Effects of Drugs. Oxford University Press: New York.

Beiser M, Bean G, Erickson D, Zhang J, Iacono WG, Rector NA (1994). Biological and psychosocial predictors of job performance following a first episode of psychosis. Am J Psychiatry 151: 857-863.

Bond AJ, Lader MH (1974). The use of analogue scales in rating subjective feelings. Br Med J 47: 211-218.

Braff DL, Geyer MA, Swerdlow NR (2001). Human studies of prepulse inhibition of startle: normal subjects, patient groups, and pharmacological studies. Psychopharmacology (Berl) 156: 234-258.

Brocks DR (1999). Anticholinergic drugs used in Parkinson's disease: an overlooked class of drugs from a pharmacokinetic perspective. J Pharm Pharm Sci 2: 39-46.

Broerse A, Crawford TJ, den Boer JA (2001). Parsing cognition in schizophrenia using saccadic eye movements: a selective overview. Neuropsychologia 39: 742-756.

Calkins ME, Iacono WG (2000). Eye movement dysfunction in schizophrenia: a heritable characteristic for enhancing phenotype definition. Am J Med Genet 97: 72-76.

Carpenter RHS (1988). Movements of the Eyes. Pion: London.

Clementz BA (1998). Psychophysiological measures of (dis) inhibition as liability indicators for schizophrenia. Psychophysiology 35: 648-668.

Clementz BA, Sweeney JA, Hirt M, Haas G (1990). Pursuit gain and saccadic intrusions in first-degree relatives of probands with schizophrenia. J Abnorm Psychol 99: 327-335.

Cohen J (1988). Statistical Power Analysis for the Behavioral Sciences. Lawrence Earlbaum Associates Inc.: Hillsdale, NJ.

Coull JT (1998). Neural correlates of attention and arousal: insights from electrophysiology, functional neuroimaging and psychopharmacology. Prog Neurobiol 55: 343-361.

Crawford TJ, Haeger B, Kennard C, Reveley MA, Henderson L (1995a). Saccadic abnormalities in psychotic patients. I. Neuroleptic-free psychotic patients. Psychol Med 25: 461-471.

Crawford TJ, Haeger B, Kennard C, Reveley MA, Henderson L (1995b). Saccadic abnormalities in psychotic patients. II. The role of neuroleptic treatment. Psychol Med 25: 473-483.

Crawford TJ, Henderson L, Kennard C (1989). Abnormalities of nonvisually-guided eye movements in Parkinson's disease. Brain 112(Part 6): 1573-1586.

Crawford TJ, Sharma T, Puri BK, Murray RM, Berridge DM, Lewis SW (1998). Saccadic eye movements in families multiply affected with schizophrenia: the Maudsley Family Study. Am J Psychiatry 155: 1703-1710.

Dépatie L, O'Driscoll GA, Holahan AL, Atkinson V, Thavundayil JX, Kin NN et al (2002). Nicotine and behavioral markers of risk for schizophrenia: a double-blind, placebo-controlled, crossover study. Neuropsychopharmacology 27: 1056-1070.

Deutch AY, Roth RH (1999). Neurotransmitters. In: Zigmond MJ, Bloom FE, Landis SC, Roberts JL, Squire LR (eds). Fundamental Neuroscience. Academic Press: San Diego. pp 193-234.

Ettinger U, Kumari V, Crawford TJ, Davis RE, Sharma T, Corr PJ (2003). Reliability of smooth pursuit, fixation, and saccadic eye movements. Psychophysiology 40: 620-628.

Everitt BJ, Robbins TW (1997). Central cholinergic systems and cognition. Annu Rev Psychol 48: 649-684.

First MB, Spitzer RL, Gibbon M, Williams JBW (1996). Structured Clinical Interview for DSM-IV Axis I Disorders Research Version (SCID-I). State Psychiatric Institute, Biometrics Research: New York.
Francis PT, Palmer AM, Snape M, Wilcock GK (1999). The cholinergic hypothesis of Alzheimer's disease: a review of progress. J Neurol Neurosurg Psychiatry 66: 137-147.

Friedman JI, Temporini H, Davis KL (1999). Pharmacologic strategies for augmenting cognitive performance in schizophrenia. Biol Psychiatry 45: 1-16.

Gooding DC, Iacono WG, Beiser M (1994). Temporal stability of smooth-pursuit eye tracking in first-episode psychosis. Psychophysiology 31: 62-67.

Green JF, King DJ, Trimble KM (2000). Antisaccade and smooth pursuit eye movements in healthy subjects receiving sertraline and lorazepam. J Psychopharmacol 14: 30-36.

Harvey PD, Moriarty PJ, Serper MR, Schnur E, Lieber D (2000). Practice-related improvement in information processing with novel antipsychotic treatment. Schizophr Res 46: 139-148.

Hutton SB, Cuthbert I, Crawford TJ, Kennard C, Barnes TR, Joyce EM (2001). Saccadic hypometria in drug-naive and drug-treated schizophrenic patients: a working memory deficit? Psychophysiology 38: 125-132.

Katsanis J, Iacono WG, Beiser M (1996). Eye-tracking performance and adaptive functioning over the short-term course of firstepisode psychosis. Psychiatry Res 64: 19-26.

Kay SR, Fiszbein A, Opler LA (1987). The positive and negative syndrome scale (PANSS) for schizophrenia. Schizophr Bull 13: 261-276.

Kennard C, Crawford TJ, Henderson L (1994). A pathophysiological approach to saccadic eye movements in neurological and psychiatric disease. J Neurol Neurosurg Psychiatry 57: 881-885.

Klein C, Fischer Jr B, Fischer B, Hartnegg K (2002). Effects of methylphenidate on saccadic responses in patients with ADHD. Exp Brain Res 145: 121-125.

Kristjánsson Á, Chen Y, Nakayama K (2001). Less attention is more in the preparation of antisaccades, but not prosaccades. Nat Neurosci 4: 1037-1042.

Kumari V (2000). A human perspective: commentary on Swerdlow et al, 'Animal models of deficient sensorimotor gating: what we know, what we think we know, and what we hope to know soon'. Behav Pharmacol 11: 209-210.

Kumari V, Zachariah E, Galea A, Jones HC, Das M, Mehrotra R et al (2003). Effects of acute procyclidine administration on prepulse inhibition of the startle response in schizophrenia: a doubleblind, placebo-controlled study. J Psychopharmacol 17: 95-101.

Kumari V, Zachariah E, Galea A, Mehrotra R, Taylor D, Sharma T (2001). Effects of procyclidine on prepulse inhibition of the acoustic startle response in healthy human volunteers. Psychopharmacology (Berl) 154: 221-229.

Kurtz MM, Moberg PJ, Mozley LH, Hickey T, Arnold SE, Bilker WB et al (2001). Cognitive impairment and functional status in elderly institutionalized patients with schizophrenia. Int $J$ Geriatr Psychiatry 16: 631-638.

Leboyer M, Bellivier F, Nosten-Bertrand M, Jouvent R, Pauls D, Mallet J (1998). Psychiatric genetics: search for phenotypes. Trends Neurosci 21: 102-105.

Leigh RJ, Zee DS (1999). The Neurology of Eye Movements. Oxford University Press: Oxford.

Lencer R, Malchow CP, Krecker K, Nolte A, Pinnow M, von Siefart SZ et al (1999). Smooth pursuit performance in families with multiple occurrence of schizophrenia and nonpsychotic families. Biol Psychiatry 45: 694-703.

Leonard BE (1997). Fundamentals of Psychopharmacology. Wiley: Chichester.

Levy DL, Holzman PS, Matthysse S, Mendell NR (1994). Eye tracking and schizophrenia: a selective review. Schizophr Bull 20: 47-62.

McDowell JE, Clementz BA (1997). The effect of fixation condition manipulations on antisaccade performance in schizophrenia: studies of diagnostic specificity. Exp Brain Res 115: 333-344. 
McGaughy J, Everitt BJ, Robbins TW, Sarter M (2000). The role of cortical cholinergic afferent projections in cognition: impact of new selective immunotoxins. Behav Brain Res 115: 251-263.

Mindham RH, Lamb P, Bradley R (1977). A comparison of piribedil, procyclidine and placebo in the control of phenothiazine-induced parkinsonism. Br J Psychiatry 130: 581-585.

Mitchell JP, Macrae CN, Gilchrist ID (2002). Working memory and the suppression of reflexive saccades. J Cogn Neurosci 14: 95-103.

Mori K, Yamashita H, Nagao M, Horiguchi J, Yamawaki S (2002). Effects of anticholinergic drug withdrawal on memory, regional cerebral blood flow and extrapyramidal side effects in schizophrenic patients. Pharmacopsychiatry 35: 6-11.

Müri RM, Heid O, Nirkko AC, Ozdoba C, Felblinger J, Schroth G et al (1998). Functional organisation of saccades and antisaccades in the frontal lobe in humans: a study with echo planar functional magnetic resonance imaging. J Neurol Neurosurg Psychiatry 65: 374-377.

O’Driscoll GA, Lenzenweger MF, Holzman PS (1998). Antisaccades and smooth pursuit eye tracking and schizotypy. Arch Gen Psychiatry 55: 837-843.

Ott J (1991). Analysis of Human Genetic Linkage. Johns Hopkins University Press: Baltimore/London.

Radant AD, Hommer DW (1992). A quantitative analysis of saccades and smooth pursuit during visual pursuit tracking. A comparison of schizophrenics with normals and substance abusing controls. Schizophr Res 6: 225-235.

Reulen JP, Marcus JT, van Gilst MJ, Koops D, Bos JE, Tiesinga G et al (1988). Stimulation and recording of dynamic pupillary reflex: the IRIS technique. Part 2. Med Biol Eng Comput 26: 27-32.

Roberts RJ, Hager LD, Heron C (1994). Prefrontal cognitive processes: working memory and inhibition in the antisaccade task. J Exp Psychol: General 123: 374-393.

Roitman SE, Keefe RS, Harvey PD, Siever LJ, Mohs RC (1997). Attentional and eye tracking deficits correlate with negative symptoms in schizophrenia. Schizophr Res 26: 139-146.

Ross DE (2000). The deficit syndrome and eye tracking disorder may reflect a distinct subtype within the syndrome of schizophrenia. Schizophr Bull 26: 855-866.

Ross RG, Olincy A, Harris JG, Radant A, Adler LE, Compagnon N et al (1999a). The effects of age on a smooth pursuit tracking task in adults with schizophrenia and normal subjects. Biol Psychiatry 46: 383-391.

Ross RG, Olincy A, Radant A (1999b). Amplitude criteria and anticipatory saccades during smooth pursuit eye movements in schizophrenia. Psychophysiology 36: 464-468.

Schwartz BD, Tomlin HR, Evans WJ, Ross KV (2001). Neurophysiologic mechanisms of attention: a selective review of early information processing in schizophrenics. Front Biosci 6: D120-D134.

Sharma T, Galea A, Zachariah E, Das M, Taylor D, Ruprah M et al (2002). Effects of $10 \mathrm{mg}$ and $15 \mathrm{mg}$ oral procyclidine on critical flicker fusion threshold and cardiac functioning in healthy human subjects. J Psychopharmacol 16: 181-185.

Sharma T, Harvey P (2000). Cognition in Schizophrenia. Oxford University Press: Oxford.

Spaulding WD, Fleming SK, Reed D, Sullivan M, Storzbach D, Lam M (1999). Cognitive functioning in schizophrenia: implications for psychiatric rehabilitation. Schizophr Bull 25: 275-289.

Spohn HE, Strauss ME (1989). Relation of neuroleptic and anticholinergic medication to cognitive functions in schizophrenia. J Abnorm Psychol 98: 367-380.

Stuyven E, Van der Goten K, Vandierendonck A, Claeys K, Crevits L (2000). The effect of cognitive load on saccadic eye movements. Acta Psychol (Amst) 104: 69-85.

Sweeney JA, Clementz BA, Haas GL, Escobar MD, Drake K, Frances AJ (1994). Eye tracking dysfunction in schizophrenia: characterization of component eye movement abnormalities, diagnostic specificity, and the role of attention. J Abnorm Psychol 103: 222-230.

Swerdlow NR, Braff DL, Geyer MA (2000). Animal models of deficient sensorimotor gating: what we know, what we think we know, and what we hope to know soon. Behav Pharmacol 11: 185-204.

Waxham MN (1999). Neurotransmitter receptors. In: Zigmond MJ, Bloom FE, Landis SC, Roberts JL, Squire LR (eds). Fundamental Neuroscience. Academic Press: San Diego. pp 235-267.

Whiteman PD, Fowle AS, Hamilton MJ, Peck AW, Bye A, Dean K et al (1985). Pharmacokinetics and Pharmacodynamics of procyclidine in man. Eur J Clin Pharmacol 28: 73-78.

Zachariah E, Kumari V, Galea A, Das M, Mehrotra R, Taylor D et al (2002). Effects of oral procyclidine administration on cognitive functions in healthy subjects: implications for schizophrenia. J Clin Psychopharmacol 22: 224-226. 